and others, rather like today's use of the Latin script to write European languages. Brown advances economic, linguistic and administrative arguments for the gradual disappearance of cuneiform from its former heartland around Babylon, the capital of Babylonia.

Economically, Babylon declined in importance when Alexander's alleged plan to make the city the capital of Asia failed to transpire after his death in 323 вс. The city was also bypassed to the north by new desert trade routes from Asia to the Med-

iterranean, which opened up with the domestication of the camel as a pack animal. The use of Babylon's cuneiform script therefore diminished in commercial transactions.

Linguistically, Babylonian cuneiform was disadvantaged in comparison with alphabetic scripts. It was cumbersome, requiring hundreds of signs - a mixture of syllables and word symbols known as

logograms - and used a clay medium. Unlike the alphabets used to write Greek, Phoenician and Aramaic, Babylonian cuneiform could not be written rapidly, cursively or conveniently with a brush on papyrus or other lightweight materials. Nevertheless, cuneiform was sometimes adapted to write alphabets. Such was its prestige that the Persian conquerors of Babylon invented a new cuneiform alphabet for their own language, now known as Old Persian.

Administratively, however, the Persian empire preferred the Aramaic script to any kind of cuneiform. Originally a Semitic language of ancient Syria, Aramaic had become the lingua franca of the Middle East by the sixth century BC. Later, it was the vernacular language of Jesus Christ and the Apostles and is used in the Dead Sea Scrolls. Aramaic eventually displaced cuneiform, which found its last refuge in astrology. Brown tells how scribes working in the collapsing temples of Babylon still, as late as the first century AD, "exploit[ed] a shrinking market for old-fashioned Babylonian astrology in cuneiform", even though they no longer wrote in an elegant hand.

The Aramaic script was itself extinguished in the seventh century AD by the Arabic script, which developed from Aramaic via the script of the Nabataeans, who ruled from Petra in Jordan. Arabic eliminated many pre-existing South Semitic alphabets that had been invented by literate but bored desert nomads in the Arabian peninsula before the arrival of Islam - a subtle process that is well explained in Michael Macdonald's essay. The association of the Arabic script with the prestige of Islam and the Koran was the determining factor in its triumph.

In south Asia, by contrast, a unifying script has not been important. Most modern Indian scripts derive from one ancestor, Brahmi, first attested in the third century $\mathrm{BC}$ in the rock edicts of Ashoka at various sites in Pakistan and northern India. Yet Sanskrit, the language of the Hindu scriptures, has been written in many Indian scripts, including south Indian Grantha and Devanagari. Similarly, the Pali language of Buddhist scriptures is written in the Sinhala, Thai, Burmese and Khmer scripts, among others. This availability of alternatives, says Richard Salomon in his essay, explains why the early Kharosthi script - probably an Indian derivative of Aramaic - could be abandoned with the decline of the Kushan empire that used it, despite its use in Sanskrit and Buddhist texts between the third century BC and the third century AD. Perhaps because of the country's pluralistic traditions, India has chosen not to define its culture by a single script, unlike China and the Arab world.

One wonders whether China's enduring political unity may partly account for the longevity of Chinese characters, a subject that is somewhat neglected by the book. The classical Chinese script enjoys high respect because of its antiquity - it is descended from the recognizable characters inscribed on 'oracle bones' of the Shang civilization from 1200 BC - and because of its imperial and artistic associations. When the former Chinese leader Mao Zedong, himself a calligrapher, proposed to romanize the Chinese script in the 1950s to educate the masses, he was forced by the literati to compromise with the introduction of a simplified character script and a parallel romanized phonetic system known as Pinyin. In Japan, several thousand Chinese characters were integrated with two sets of indigenous syllabic signs during the first five centuries AD to make one prestigious writing system. Despite the difficulties of writing Chinese and Japanese, neither script looks likely to disappear any time soon under the onslaught of alphabetic triumphalism.

The Disappearance of Writing Systems reveals that commerce, culture, language, medium, power, prestige and religion, in varying combinations, are all implicated in the disappearance of scripts. Each languagescript combination raises issues that cannot be understood from linguistic considerations alone. We know more about script death than script birth, but no single theory can encompass why scripts flourish or vanish.

Andrew Robinson is a visiting fellow of Wolfson College, Cambridge CB3 9BB, UK, and author of The Story of Writing and Lost Languages: The Enigma of the World's Undeciphered Scripts. e-mail:ar471@cam.ac.uk

\title{
New look at cancer drugs
}

\section{Durchleuchtet \\ Artpoint 222, Vienna, Austria \\ 25 October until 27 November 2008}

Margaret Oechsli goes on extraordinary journeys with her microscope. Peering at a smudge of a dried chemical, such as crystallized glutamic acid, she probes the refracted light looking for artistic inspiration. "I have no control over what I see in the microscope," she says in a rich Polish accent. But what she finds and photographs is stunning. She has created more than 3,000 images, shimmering geometries and colourful landscapes that look more like paintings than photos.

Oechsli's abstract studies of microscopic chemical structures will be shown in a new exhibition called Durchleuchtet, starting this week at Artpoint 222 in Vienna. Each image explores a cancer drug - such as tamoxifen, oxaliplatin, herceptin and others - that Oechsli handles in her day job as a clinical research coordinator in the Heart and Lung Institute at Jewish Hospital in Louisville, Kentucky.

The medical theme complements the fund-raising goal of Durchleuchtet - which in German means both 'illuminated with light' and 'X-rayed'. Oechsli's photos will be auctioned alongside artistically rendered radiographs of Austrian athletes, and the proceeds will benefit the charity Médecins Sans Frontières (Doctors Without Borders).

Although her background in science has 


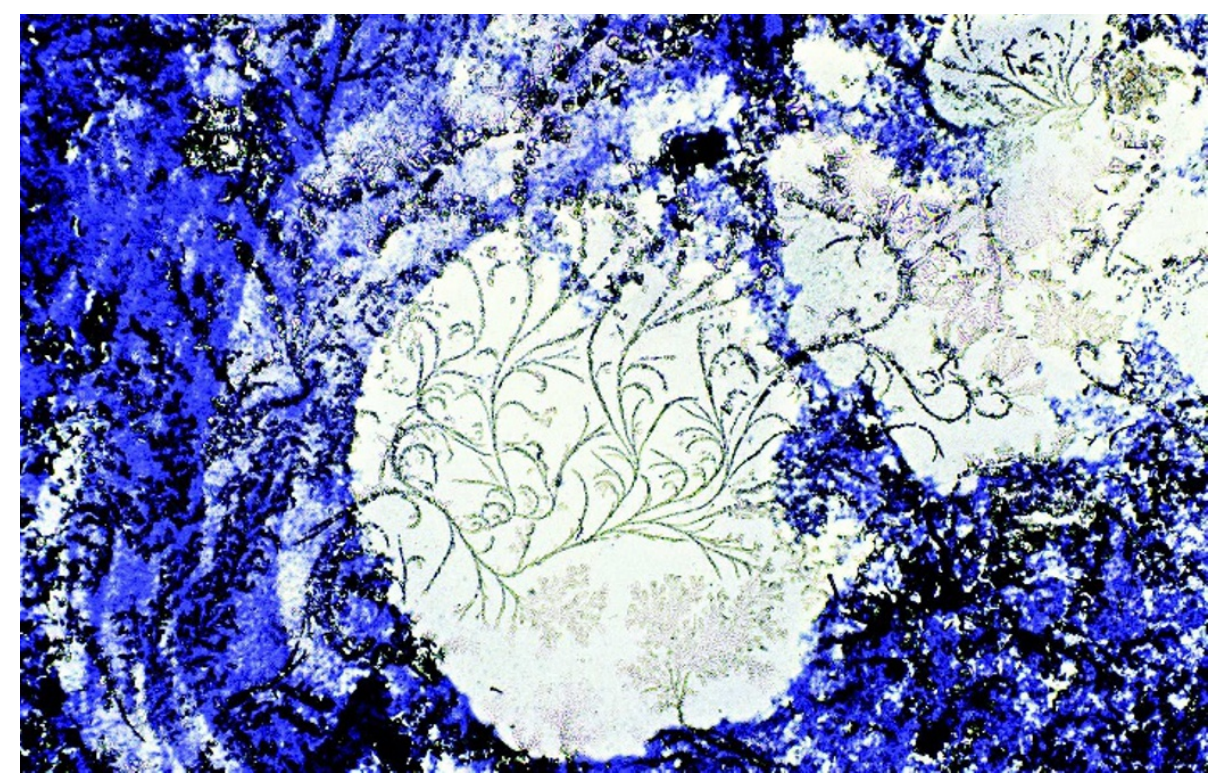

Oechsli's Untested Beliefs highlights the magnified fern-like branching of atropine, a muscle relaxant.

honed her techniques, Oechsli is drawn to the kaleidoscopic images for their own sake. An art lover, her most powerful photographs evoke familiar styles from famous abstract painters. "It pops to my mind that this style or this composition or this colour looks like [Robert] Motherwell or [Joan] Miró", she says. Some resemble still-life pictures - in Dance Double, magnified L-isoleucine morphs into ballet slippers dangling from their laces. Others are purely aesthetic. The technicolour leopard-skin knives of L-glutamic acid pierce into black voids in a dramatic work she calls Easter Island Fugue.

Oechsli considers herself an artist, but embraces the parallels between her two worlds. "Science is art and art is science," she says. "In both areas you have to be very disciplined. And both of those disciplines have no finish line."

Brendan Maher is Features and Commentary editor for Nature.

\section{Bioethics laid bare}

\author{
Future Bioethics: Overcoming Taboos, \\ Myths, and Dogmas \\ by Ronald A. Lindsay \\ Prometheus Books: 2008. 291 pp \\ $\$ 28.95 / £ 19.50$
}

Bioethical debate has seldom been more vibrant, or more important. Although some people dispute whether it is even a discipline, bioethics claims the high ground by tackling some of the most complex and sensitive issues confronting modern society. From discussions about abortion to end of life, bioethicists are there. They carry the flag for informed and contentious argument, be it over assisted reproduction, cloning or stemcell research. Ronald Lindsay, a lawyer with a doctorate in bioethics, is particularly well placed to bring his voice to the arena in his new book, Future Bioethics.
Given the range of topics that bioethicists cover, it is not surprising that emotions in the field run high. Discussions often begin from controversial positions that are entrenched in dogma. As the book's subtitle suggests, Lindsay's mission is to expose and debunk these myths. He does so in a book that is readable rather than obscure, and accessible to the interested lay person as well as to scholars in the field. Reckoning that progress is unlikely unless we can identify some common moral ground, he postulates that argument based on agreed norms can break the deadlock created by over-hyped language and untested dogma. What is needed, he argues, is "a wellreasoned, pragmatic approach to controversies in bioethics that avoids reliance on taboos, myths and dogma, whether these result from religious or ideological beliefs". These are fighting words, and Lindsay throws a number of powerful punches.
He starts by introducing the reader to his theoretical approach, which hinges on finding common ground and then applying 'common-sense reasoning' to it. Lindsay considers the main schools of moral reasoning and their inherent problems, and goes on to consider the relationship between morals and the law. He concludes that we must take account of moral norms, but shows that we also need to consider whether these are or can be incorporated into law, and if so, how.

After noting that bioethics embraces a wide range of topics, Lindsay selects five areas for consideration. For a European reader, the selection is somewhat unusual, but nonetheless fascinating. The least surprising inclusion is assisted dying. Given Lindsay's concern with debunking myths, it is an obvious starting point because debate in this area is often bound by entrenched ideological positions. Lindsay provides a thorough and entertaining account of the arguments that are dusted off by opponents whenever someone builds a case for allowing assisted dying. When legalization is opposed using the argument for the sanctity of life, he asks whether adherence to that principle serves its intended goal in all cases. For example, whereas we all agree that taking a life is wrong on the face of it, we may adopt this view because we assume the life is wanted by the person living it. He suggests that by pronouncing it is always wrong to take a life, even when that life may no longer be desired, is to misunderstand the obligations derived from the principle of respecting, protecting and furthering the interests of others. Thus, in exceptional cases where great suffering is involved and death is inevitable, he concludes that "death is not necessarily prejudicial to that person's interests".

It is with the 'slippery slope' argument against legislation that Lindsay engages most convincingly. Challenging the argument's theoretical basis, he points to evidence showing that allowing assisted dying does not inevitably mean that 'vulnerable' groups, such as the elderly or people with disabilities, would find themselves driven to seek death

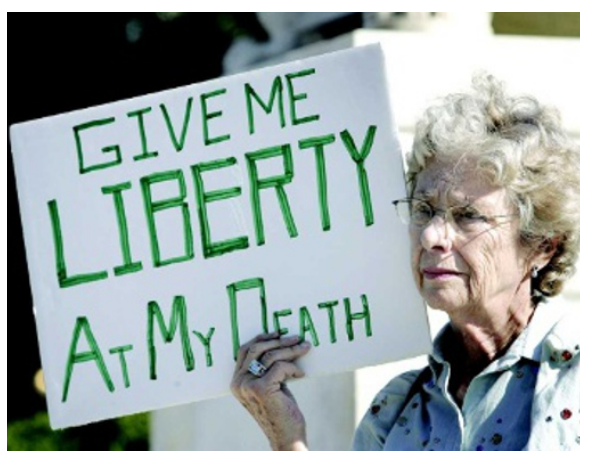

